\title{
Body Composition in Tribal Indian Girls from the North-East India
}

\author{
Vaman V. Khadilkar ${ }^{1} \cdot$ Anuradha V. Khadilkar ${ }^{1}$ (D) \\ Received: 25 March 2019 / Accepted: 9 April 2019 / Published online: 22 April 2019 \\ (C) Dr. K C Chaudhuri Foundation 2019
}

Measurement of body composition is an essential part of nutritional assessment of an individual. Studies report that body fat in Indian children is higher for a given body mass index than in western populations [1]. Body fat tends to increase with age in girls and various factors such as dietary intake, physical activity, pubertal stage and ethnicity influence the body composition. India being a diverse country, body composition of Indian girls is likely to be different in different geographical regions, such as is reported in the current study [2].

There is very little data on body composition of tribal girls, though tribals make up around $8.6 \%$ of the total population. In the current study by Saha et al., in 6-12 y-old Chakma girls, authors found that girls from the Chakma tribe from Tripura had higher body fat till around $9 \mathrm{y}$ of age, after which they were comparable to non-tribal Bengali girls [2]. Santhal girls had a body fat percentage which was much lower than that of the Chakma girls at all age groups [3], including at $12 \mathrm{y}$ (10.8\% in Santhal girls vs. $18.4 \%$ in Chakma girls). Interestingly, body fat was much higher in rural Karbi Anglong adolescent girls from Assam, being 23.5\% at $10 \mathrm{y}$ and $26.1 \%$ at 12 y [4]. On comparing the body mass indices, they were very similar in Chakma girls

Vaman V. Khadilkar

vamankhadilkar@gmail.com

1 Growth and Pediatric Endocrine Unit, Hirabai Cowasji Jehangir Medical Research Institute, Jehangir Hospital,

Pune, Maharashtra 411001, India
(14.3 to $17.7 \mathrm{~kg} / \mathrm{m}^{2}, 6-12 \mathrm{y}$ ), non-tribal Bengali girls (13.1 to $17.3 \mathrm{~kg} / \mathrm{m}^{2}, 6-12 \mathrm{y}$ ), Santhal girls (14.0 to $17.3 \mathrm{~kg} / \mathrm{m}^{2}$ from 6 to 12 y) and Karbi Anglong girls (16.5 to $\left.17.8 \mathrm{~kg} / \mathrm{m}^{2}, 10-12 \mathrm{y}\right)$. Thus, at a relatively similar BMI, varying body fat percentages have been reported in tribal and rural girls from the North-east, indicating the importance of measuring body composition in these girls.

It is important to identify reasons for the differences in body fat in the two sets of girls that Saha et al. have studied. Authors have collected data on socioeconomic status and all the girls belonged to low socioeconomic status as per the Kuppuswamy classification. Thus, socioeconomic status was less likely to be the reason for differences in body fat that the authors found. However, to identify factors which were responsible for differences in body composition of two sets of girls, dietary intake and physical activity data would have been very useful. Further, Chakma girls had higher body fat in younger years, while the fat percentage was similar at $12 \mathrm{y}$. It is thus likely that the Chakma girls went into puberty early; examination for pubertal maturity in community based studies though difficult, is required to shed light on changes in body composition. Further, comparison of anthropometric parameters with healthy Indian girls by calculating age matched Z-scores would have highlighted the growth impairments in the children studied [5].

Further studies in tribal children and adolescents from the North-East are required to understand growth and body composition in these children. Such studies, including longitudinal studies will go a long way in optimizing growth and body composition in tribal children. 


\section{Compliance with Ethical Standards}

Conflict of Interest None.

\section{References}

1. Pandit D, Khadilkar A, Khadilkar V. Body fat percentages by dualenergy X-ray absorptiometry corresponding to body mass index cutoffs for overweight and obesity in Indian children. Clin Med Pediatr. 2009;3:55-61.

2. Saha S, Sil SK. A comparative study on fat pattern between tribal and non-tribal girls of Tripura, north-east India. Indian J Pediatr. 2019. https://doi.org/10.1007/s12098-019-02879-7 [Epub ahead of print].
3. Chowdhury SD, Chakraborti T, Ghosh T. Fat patterning of Santhal children: a tribal population of West Bengal, India. J Trop Pediatr. 2007;53:98-102.

4. Sharma J, Mondal N. Physical growth and body composition assessment among rural adolescent girls (10-16 years) of Karbi Anglong, Assam, Northeast India. J Life Sci. 2018;10: $16-28$.

5. Indian Academy of Pediatrics Growth Charts Committee; Khadilkar V, Yadav S, Agrawal KK, et al. Revised IAP growth charts for height, weight and body mass index for 5- to 18-year-old Indian children. Indian Pediatr. 2015;52:47-55.

Publisher's Note Springer Nature remains neutral with regard to jurisdictional claims in published maps and institutional affiliations. 